\title{
Analisis Kecanduan Game Player Unknown's Battlegrounds (PUBG) Mobile dengan Menggunakan Logika Fuzzy
}

\author{
Mochammad Ilham Rofiqi ${ }^{1}$, Hindarto Hindarto, \\ ${ }^{1,2}$ Jurusan Informartika, Fakultas Sains dan Teknologi, Universitas Muhammadiyah Sidoarjo \\ hindarto@umsida.ac.id
}

\begin{abstract}
Abstrak
Perkembangan game saat ini sangatlah pesat khususnya game mobile. Game dengan game play sederhana, singkat, dan mudah diakses lebih sering dimainkan dibanding game yang menawarkan permainan kompleks. Salah satunya ialah game PlayerUnknown's Battlegrounds Mobile (PUBG Mobile) game yang sudah di unduh mencapai 400 juta pada tahun 2019 dan pengguna harian game ini mencapai 50 juta pengguna. Dengan menggunakan metode logika fuzzy tsukamoto untuk mengukur seberapa kecanduan seorang bermain game ini. Data yang diambil dari beberapa pengguna game PlayerUnknown's Battlegrounds Mobile (PUBG Mobile) kemudian dianalisis dengan menggunakan metode logika fuzzy tsukamoto dan dilakukan perhitungan guna mendapatkan kesimpulan yang tepat dan sesuai dengan yang diharapkan. Dari 100 data yang dilakukan mempunyai output denagn kecanduan rendah sebesar 50\%, kecanduan sedang sebesar 20\% dan kecanduan tinggi sebesar 30\%.
\end{abstract}

Kata Kunci - kecanduan game, logika fuzzy, tsukamoto, player unknown's battlegrounds mobile

\section{Pendahuluan}

Saat ini perkembangan kemajuan teknologi informasi semakin cepat dan pesat salah satunya ialah teknologi internet dan komputer (Ratnasari, 2004). Hampir setiap kalangan menggunakan kemajuan teknologi ini mulai dari yang tua sampai muda semua menggunakan jaringan internet. Dan internet juga mempunyai dampak negatif dan positif tergantung penggunannya. Bermacam-macam informasi mudah diperoleh secara langsung dari internet secara cepat. Bukan hanya itu saja, media hiburan mulai dari vidio ataupun foto juga mudah diakses oleh internet (Ngafifi, 2014).

Dari berbagai macam media hiburan yang mudah diakses game online juga sekarang mudah diakses secara bebas (Ismi \& Akmal, 2020)(Putra et al., 2019). Pada saat ini permainan yang diakses dengan internet sedang marak maraknya dikalangan masyarakat terutama bagi anak-anak sampai remaja. Permainan yang diakses secara online secara umum diperuntukkan untuk mengusir kebosanan dan hanya sekedar untuk menyegarkan pikiran setelah melakukan aktifitas. Walaupun kenyataanya permainan online malah membuat orang-orang kecanduan memainkan game ini. seringnya bermain secara terus-terusan membuat seorang terkena kecanduan bermain game yang berdampak pada tingkah laku (Masya \& Candra, 2016)(Ayu \& Saragih, 2016).

Kecanduan game online membuat para pemain lebih banyak menghabiskan waktu didepan komputer ataupun handphone sehingga menghambat interaksi dengan sekitar. Dan juga game online mempunyai banyak dampak mulai dari kurangnya berdapatasi sosial yang mengakibatkan fungsi psikologi seorang dan masalah sosial antar lingkungan sekitar (Lutfiwati, 2018)(Putra et al., 2019).

Dari sekian banyak game online di internet salah satunya paling banyak dimainkan ialah game PlayerUnknown's Battlegrounds Mobile (PUBG Mobile) yang sudah diunduh sekitar 400 juta pada tahun 2019 dan pengguna harian sampai 50 juta merupakan game battle royal yang dimainkan secara online dan secara bersama-sama sehingga membuat pemain kecanduan game ini (Fauzi, 2019)(Rosalino Triyantama \& Santoso, 2019). Dengan mengguunakan metode logika fuzzy tsukamoto untuk mengukur tingkat kecanduan seorang bermain game PlayerUnknown's Battlegrounds Mobile (PUBG Mobile). Dengan memanfaatkan data para pemain game ini untuk mengukur tingkat kecanduan.

Pada penelitian ini, metode yang digunakn menggunkan metode logika Fuzzy. Logika fuzzy merupakan metode atau cara yang bisa digunakan untuk mendeteksi bebrbagai macam kegiatan, contohnya mendeteksi kapan terjadinya banjir (Arifin et al., 2016). Logika fuzzy juga bisa digunkan untuk berbagai hal yang lain (Sugianti et al., 2020)(Maulana et al., 2018)(Fiano \& Purnomo, 2017).

Tujuan penelitian ini yaitu untuk membangun sistem untuk mendeteksi kecanduan bermain game PlayerUnknown's Battlegrounds Mobile. Beberapa pembahasan yang akan disampaikan, diataranya pendahuluan, metode penelitian, hasil dan pembahasan. 


\section{Metode Penelitian}

\subsection{Analisa Data}

Pada pengunmpulan data didapat dari perigkat pada game PlayerUnknown's Battlegrounds Mobile season 3 dari berbagai server antara lain Amerika Utara, Eropa, Asia, Amerika Selatan dan KRJP (Korea dan Jepang. Pada tiap server terdapat 100 data pemain). Dari observasi yang telah dilakukan di dapat 4 data yang mendukung menentukan tingkat kecanduan seorang bermain game ini antara lain skor bertahan, skor korban, lama bertahan dan jumlah rating.

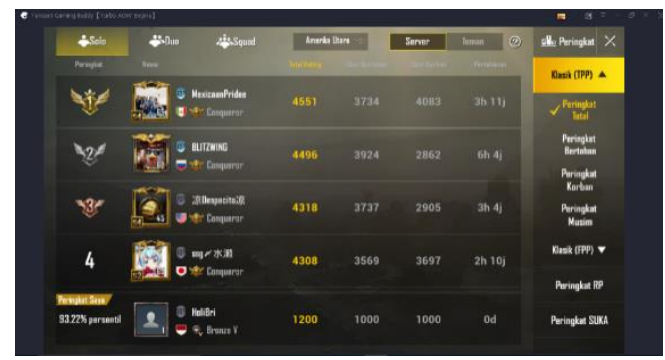

Gambar 1. Data pemain pada server Amerika Utara (Sumber: PUBG Mobile)

\subsection{Analisa Sistem}

Pada analisa sistem menggunakan teknik waterfall dari SDLC. Di dalam teknik waterfall pengerjaan pada suatu sistem dilakukan secara berurutan atau secara linier [8][9][10].

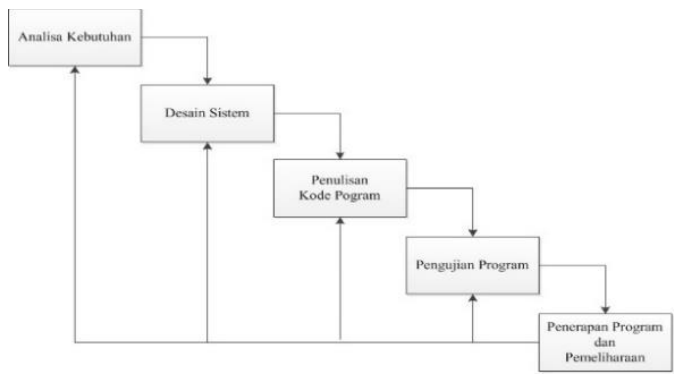

Gambar 2. Teknik waterfall

\subsection{Desain Sistem}

Pada tahap ini pengembang merancang suatu desain sistem tentang gambaran yang di inginkan oleh pemakai. Desain ini berupa use case diagram, activity diagram dan flowchart. Berikut ini merupakan tahapan desain system.

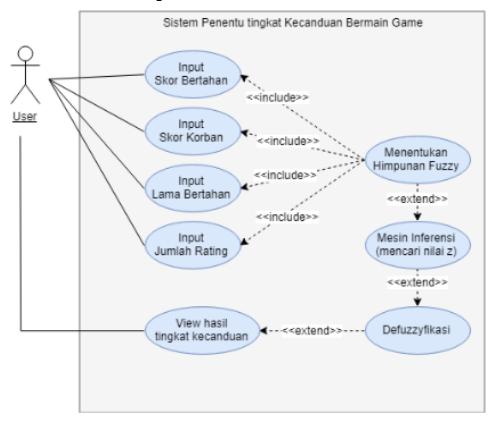

Gambar 3. Use case diagram
Dengan use case diagram ini kita bisa membuat desain aplikasi yang akan dibuat dan digunakan. Pada gambar 3 merupakan desain rancangan dari sistem penentu tingkat kecanduan bermain game.

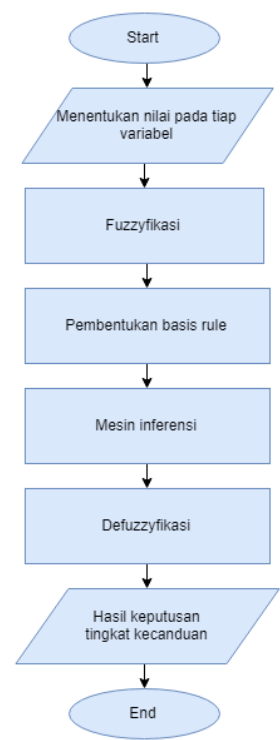

Gambar 4. Flowchart Sistem

Pada gambar 4, dijelaskan flowchart dari penentuan hasil kecanduan game dengan menggunkan logika fuzzy.

\subsection{Pembentukan Variabel dan Himpunan Fuzzy}

Pada identifikasi variabel terdapat 4 variabel input antara lain skor bertahan, skor korban, lama bertahan dan jumlah rating dan 1 variabel output antara lain kecanduan sehingga didapat himpunan fuzzy antara lain:

a. Variabel skor bertahan Tabel 1. Himpunan Fuzzy Skor Bertahan

\begin{tabular}{ccc}
\hline No & Nilai & Himpunan \\
\hline 1 & $0-3000$ & Kecil \\
2 & $2500-3500$ & Sedang \\
3 & $>3500$ & Besar \\
\hline
\end{tabular}

b. Variabel skor korban

Tabel 2. Himpunan Fuzzy Skor Korban

\begin{tabular}{ccc}
\hline No & Nilai & Himpunan \\
\hline 1 & $0-3000$ & Kecil \\
2 & $2500-3500$ & Sedang \\
3 & $>3500$ & Besar \\
\hline
\end{tabular}

c. Variabel lama bertahan

Tabel 3. Himpunan Fuzzy Lama Bertahan

\begin{tabular}{ccc}
\hline No & Nilai & Himpunan \\
\hline 1 & $0-36 \mathrm{Jam}$ & Sebentar \\
2 & 24-48 Jam & Sedang \\
3 & $>48 \mathrm{Jam}$ & Lama \\
\hline
\end{tabular}


d. Variabel jumlah rating

Tabel 4. Himpunan Fuzzy Jumlah Rating

\begin{tabular}{ccc}
\hline No & Nilai & Himpunan \\
\hline 1 & $0-4000$ & Kecil \\
2 & $3000-5000$ & Sedang \\
3 & $>3500$ & Besar \\
\hline
\end{tabular}

e. Variabel kecanduan

Tabel 5. Himpunan Fuzzy Kecanduan

\begin{tabular}{ccc}
\hline No & Nilai & Himpunan \\
\hline 1 & $0-35$ & Rendah \\
2 & $35-70$ & Sedang \\
3 & $>70$ & Tinggi \\
\hline
\end{tabular}

\section{Hasil Dan Pembahasan}

Pada tahapan ini merupakan tampilan dari sistem analisa kecanduan bermain game PlayerUnknown's Battlegrounds Mobile.

\section{a. Splash Sreen}

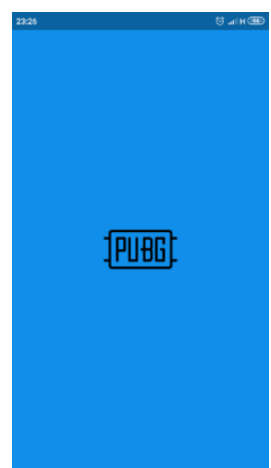

Gambar 5. Tampilan spash screen

Pada gambar diatas adalah tampilan awal ketika membuaka aplikasi splash screen. Splash Screen ini berfungsi untuk melakukan proses loading ketika aplikasi pertama kali terbuka, ketika proses loading sudah selesai splash sreen akan segara menghilang dan berganti dengan activity utama pada aplikasi.

\section{b. Form input data kecanduan}

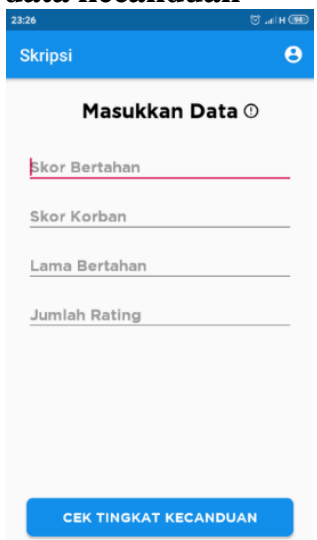

Gambar 6. Form kecanduan
Pada activity ini terdapat 4 EditText antara lain skor bertahan, skor korban, lama bertahan dan jumlah rating. EditText ini berfungsi sebagai memsasukan data kemudian dialakukan proses perhitungan tingkat kecanduan, jika salah satu EditText tidak diisi maka akan muncul peringatan error pada tiap EditText. Setelah EditText semua diisi tinggal menekan tombol "Cek Tingkat Kecanduan" kemudian muncul tingkat kecanduan pada activity Hasil Daignosa. Pada icon User yang terletak pada pojok kanan atas berfungsi untuk menampilkan profil saya pada activity profile. Dan pada icon tanda seru yang terletak disebelah "Masukan Data" berfungsi sebagai cara mencari data pengguna pada game PUBG Mobile.

\section{Hasil Diagnosa}

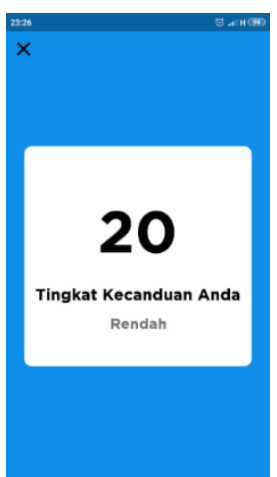

Gambar 7. Hasil diagnosa

Pada activity hasil diagnosa menampilkan 3 textview dari nilai kecanduan, 'tingkat kecanduan anda' dan hasil tingkatan rendah, sedang dan tinggi. Dari inputan activity form input data kecanduan kemudian diolah lalu muncul hasil mulai dari yang terrendah dengan nilai 0 sampai 35 , yang sedang dengan nilai 35 sampai 70 dan yang tertinggi dengan nilai 70 sampai 100 . Pada icon disebelah kiri atas berfungsi untuk kembali pada activity sebelumnya yaitu activity form kecanduan, icon kembali ini sama seperti fungsi tombol kembali pada handphone android.

\section{Activity Tutorial}

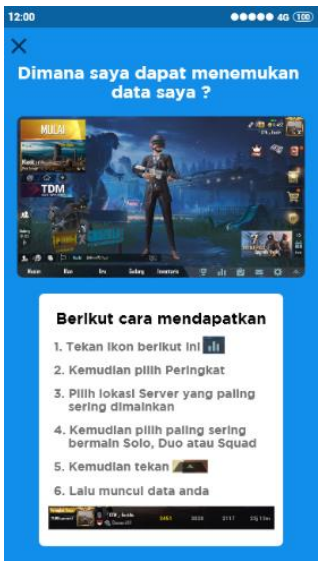

Gambar 8. Tutorial untuk aplikasi 
Pada activity tutorial berfungsi untuk pengguna yang kesulitan mencari datanya di game Playerunknown's Battlegrounds Mobile. Pada imageview menampilkan tampilan awal ketika bermain Playerunknown's Battlegrounds Mobile, kemudian diatas imageview terdapat textview yang berfungsi sebagai interaksi kepada pengguna. Dan pada bawah imageview terdapat sebuah cara-cara memperoleh data mulai dari tekan tombol kemudian memilih peringkat, memilih server kemudian memilih gameplay yang sering dimainkan lalu tekan tombol kemudian muncul data anda mulai dari skor bertahan, skor korban, lama bertahan dan jumlah rating.

\section{Contoh Perhitungan}

Untuk mengetahui tingkat kecanduan seorang pemain game PlayerUnknown's Battlegrounds Mobile diperlukan data sebagai berikut:

Skor Bertahan $=2800$

Skor Korban $=2200$

Lama Bertahan $=20$ jam

Jumlah Rating $=3200$

Dari nilai diatas berapa tingkat kecanduan pemain?

a. Mencari nilai keanggotaan tiap variabel fuzzy

1. Perhitungan nilai keanggotaan skor bertahan

Skor bertahan kecil [2800] $=3000-2800 / 3000$ $-2500=200 / 500=0,4$

Skor bertahan sedang [2800] $=2800-2500 / 3000$ $-2500=300 / 500=0,6$

2. Perhitungan nilai keangotaan skor korban

Skor korban kecil [2200] = 1

3. Perhitungan nilai keanggotaan lama bertahan

Lama bertahan kecil [20] = 1

4. Perhitungan nilai keanggotaan jumlah rating

Jumlah rating kecil $[3200]=4000-3200 / 4000-$ $3000=800 / 1000=0,8$

Jumlah rating sedang $[3200]=3200-3000 / 4000$ $-3000=200 / 1000=0.2$

b. Mencari nilai $\mathrm{z}$ pada setiap aturan dengan menggunakan fungsi MIN

1. aturan 1

[R1] IF Skor Bertahan KECIL And Skor Korban KECIL And Lama Bertahan SEBENTAR And Jumlah Rating KECIL THEN kecanduan RENDAH

$\alpha$ Predikat $1=\mu$ SkorBertahanKECIL $\cap$

$\mu$ SkorKorbanKECIL $\cap$ $\mu$ LamaBertahan SEBENTAR $\cap$

$\mu$ JumlahRating KECIL

$=\min (\mu$ SkorBertahanKECIL[2800], $\mu$ SkorKorbanKECIL[2200], $\mu$ LamaBertahan SEBENTAR[20], $\mu J u m l a h$ Rating KECIL[3200])

$=\min (0,4 ; 1 ; 1 ; 0,8)$

$=0,4$

Himpunan Kecanduan RENDAH

$35-\mathrm{z} / 35-20=35-\mathrm{z} / 15=0,4$

$0,4 \times 15=35-\mathrm{Z}$
2. Aturan 2

$$
\begin{aligned}
& 6=35-z \\
& z=35-6 \\
& z=29------>z 1=29
\end{aligned}
$$

[R29] IF Skor Bertahan SEDANG And Skor Korban KECIL And

Lama Bertahan SEBENTAR And Jumlah

Rating SEDANG

THEN kecanduan RENDAH

$\alpha$ Predikat $2=\mu$ SkorBertahanSEDANG $\cap$

$\mu$ SkorKorbanKECIL $\cap$

$\mu$ LamaBertahan SEBENTAR $\cap$

$\mu J u m l a h R a t i n g$ SEDANG

$=\min (\mu$ SkorBertahanSEDANG[2800], $\mu$ SkorKorbanKECIL[2200], $\mu$ LamaBertahan SEBENTAR[20], $\mu J u m l a h R a t i n g$ SEDANG[3200])

$=\min (0,6 ; 1 ; 1 ; 0,2)$

$=0,2$

Himpunan Kecanduan RENDAH

$35-\mathrm{z} / 35-20=35-\mathrm{z} / 15=0,2$

$0,2 \times 15=35-z$

$3=35-z$

$\mathrm{z}=35-3$

$\mathrm{z}=32$-------> z2 $=32$

c. Mencari berapa nilai $\mathrm{z}$ atau defuzzyfikasi

$\mathrm{Z}=\frac{0,4 * 29+0,2 * 32}{0,4+0,2}$

$=18 / 0,6$

$=30$

Jadi berdasarkan data yang diperoleh bahwa prediksi tingkat kecanduan bermain game PlayerUnknown's Battlegrounds Mobile adalah 30 (rendah).

\section{Kesimpulan dan Saran}

Dengan menggunakan metode logika fuzzy pada aplikasi analisa tingkat kecanduan bermain game PUBG, apikasi yang telah dibuat bisa membantu para pemain game PUBG mengetahui seberapa besar tingkat kecanduannya bermain game PUBG. Dari 100 data yang dilakukan mempunyai output denagn kecanduan rendah sebesar 50\%, kecanduan sedang sebesar $20 \%$ dan kecanduan tinggi sebesar $30 \%$.

Daftar Pustaka:

Arifin, S., Muslim, M. A., \& Sugiman, S. (2016). "Implementasi Logika Fuzzy Mamdani untuk Mendeteksi Kerentanan Daerah Banjir di Semarang Utara". Scientific Journal of Informatics, 2(2), 179. https://doi.org/10.15294/sji.v2i2.5086

Ayu, L., \& Saragih, S. (2016). "Interaksi Sosial dan Konsep Diri dengan Kecanduan Games Online pada Dewasa Awal". Persona:Jurnal Psikologi Indonesia, 5(02), 167-173. https://doi.org/10.30996/persona.v5i02.734

Fauzi, A. (2019). "PENGARUH GAME ONLINE 
PUBG (Player Unknown's Battle Ground) TERHADAP PRESTASI BELAJAR PESERTA DIDIK". ScienceEdu, II(1), 61. https://doi.org/10.19184/se.v2i1.11793

Fiano, D. S. I., \& Purnomo, A. S. (2017). "Sistem Pakar Untuk Mendeteksi Tingkat Resiko Penyakit Jantung Dengan Fuzzy Inferensi (Mamdani)". INFORMAL : Informatics Journal, 2(2), 64-78.

Ismi, N., \& Akmal, A. (2020). "Dampak Game Online Terhadap Perilaku Siswa di Lingkungan SMA Negeri 1 Bayang". Journal of Civic Education, 3(1), 1-10. https://doi.org/10.24036/jce.v3i1.304

Lutfiwati, S. (2018). "Memahami Kecanduan Game Online Melalui Pendekatan Neurobiologi". Journal of Sychology, 1(1), 1-16. http://ejournal.radenintan.ac.id/index.php/anfu sina/article/view/3643/2416

Masya, H., \& Candra, D. A. (2016). "Faktor-Faktor yang Mempengaruhi Perilaku Gangguan Kecanduan Game Online pada Peserta Didik Kelas X Di Madrasah Aliyah Al Furqon Prabumulih Tahun Pelajaran 2015/2016". KONSELI: Jurnal Bimbingan Dan Konseling (E-Journal), 3(2), 97-112.

Maulana, R., Ichsan, M. H. H., \& Setyawan, G. E. (2018). "Implementasi Pengkondisian Kipas dan Lampu Otomatis Menggunakan Logika Fuzzy". Jurnal Pengembangan Teknik Informasi Dan Ilmu Komputer, 2(11), 53015309.

Ngafifi, M. (2014). "Kemajuan Teknologi Dan Pola Hidup Manusia Dalam Perspektif Sosial Budaya". Jurnal Pembangunan Pendidikan: Fondasi Dan Aplikasi, 2(1), 33-47. https://doi.org/10.21831/jppfa.v2i1.2616

Putra, F. F., Rozak, A., \& Perdana, G. V. (2019). "Dampak Game Online Terhadap Perubahan". JPI : Jurnal Politikom Indonesia, 4, 98-103.

Ratnasari, A. (2004). "Perkembangan Teknologi Komunikasi dan Kesenjangan Informasi". Mediator, 5(2), 327-336.

Rosalino Triyantama, A., \& Santoso, E. (2019). "Model Komunikasi Virtual Pemain Game PUBG MOBILE menggunakan Studi Etnografi Virtual Pada Kelompok Game PUBG MOBILE RPX E-Sport". Medium: Jurnal Ilmiah Fakultas Ilmu Komunikasi, 7(1), 5370. www.viva.co.id

Sugianti, N., Galuh, Y., Fatia, S., \& Holle, K. F. H. (2020). "Deteksi Serangan Distributed Denia of Services (DDOS) Berbasis HTTP Menggunakan Metode Fuzzy Sugeno". JISKA (Jurnal Informatika Sunan Kalijaga), 4(3), 18. https://doi.org/10.14421/jiska.2020.43-03 
Volume 7, Edisi 2, Februari 2021

$\mathbf{1 0 2} \mid \mathrm{H}$ a 1 a $\mathrm{m}$ a $\mathrm{n}$ 